\title{
Impact of Free Curcumin and Curcumin \\ Nanocapsules on Viability and Oxidative Status of Neural Cell Lines
}

BIANCA FAGAN BISSACOTTI ( $\square$ bianca_fbissacotti@hotmail.com )

Universidade Federal de Santa Maria https://orcid.org/0000-0001-6672-2530

Priscila Copetti

UFSM: Universidade Federal de Santa Maria

Samanta Gundel

UFN: Universidade Franciscana

Alencar Machado

UFN: Universidade Franciscana

Michele Sagrillo

UFN: Universidade Franciscana

Aline Ourique

UFN: Universidade Franciscana

Vera Morsch

UFSM: Universidade Federal de Santa Maria

Nathieli Bottari

UFSM: Universidade Federal de Santa Maria

Aleksandro da Silva

UDESC: Universidade do Estado de Santa Catarina

\section{Research Article}

Keywords: Curcumin, Microglia, Nanocapsules, Neurons, Safety

Posted Date: March 17th, 2021

DOl: https://doi.org/10.21203/rs.3.rs-306036/v1

License: (c) (i) This work is licensed under a Creative Commons Attribution 4.0 International License.

Read Full License

Version of Record: A version of this preprint was published at Drug and Chemical Toxicology on December 20th, 2021. See the published version at https://doi.org/10.1080/01480545.2021.2015242. 


\section{Abstract}

Curcumin is an active polyphenol substance found in the highest concentrations in the roots of Curcuma longa. Its health benefits have led to recent increases in the consumption of curcumin. It has antiinflammatory and antioxidant activities and is a potent neuroprotective against diseases of the brain. Nevertheless, its low bioavailability and its relative difficulty crossing the blood-brain barrier limit curcumin's use for these purposes. Curcumin-loaded nanoparticles may be an effective treatment for several diseases although there is a paucity of studies reporting its safety in the central nervous system (CNS). Therefore, this study aimed to identify non-neurotoxic concentrations of free curcumin and two nanoformulations of curcumin. Cell lines BV-2 and SH-SY5Y, both originating from the CNS, were evaluated after 24,48 , and $72 \mathrm{~h}$ of treatment with free curcumin and nanocapsules We measured viability, proliferation and dsDNA levels. We measured levels of reactive oxygen species and nitric oxide as proxies for oxidative stress in culture supernatants. We found that free curcumin was toxic at 10 and $20 \mu \mathrm{M}$, principally at $72 \mathrm{~h}$. Nanoformulations were more neurotoxic than the free form. Safe concentrations of free curcumin are between 1-5 $\mu \mathrm{M}$, and these concentrations were lower for nanoformulations. We determined the ideal concentrations of free curcumin and nanocapsules serving as a basis for studies of injuries that affect the CNS.

\section{Introduction}

Natural products are increasingly studied for the treatment of diseases. Curcumin is the primary active compound present in the roots of the Curcuma longa plant. This polyphenol has as anti-inflammatory, antioxidant, antimicrobial, and anticarcinogenic properties [1-4].

Curcumin may prevent or treat diseases characterized by inflammation or oxidative stress; it scavenges reactive oxygen species (ROS) chelates metal ions, and inhibits the mitogen-activating protein kinases pathway $[1,5,6]$.

Many reviews discussed the use of curcumin to treat diseases of the central nervous system (CNS), including Parkinson's, Alzheimer's, Huntington's disease, and multiple sclerosis [3, 7-10]. In an in vitro experimental model of neurodegenerative disease, Armagan and Naziroglu [11] reported the neuroprotective action of curcumin by modulating oxidative stress. In addition, this polyphenol is capable to decrease neurotoxicity, which is proven by other models of neurological disorders in vitro [11-15] and in vivo studies $[16,17]$.

Despite its substantial benefits, curcumin is toxic in high doses, at which it becomes an oxidant. The use of curcumin is also limited by low bioavailability, that results from its rapid metabolism and elimination [18-21]. Nanotechnology might overcome these limitations.

Pharmaceutical nanotechnology has been assisting researchers in developing pharmacological investigations, because nanostructures control the release of the active compound, consequently reducing toxicity and prolonging the therapeutic effect. Their characteristic size permits nanostructures 
cross barriers, including the blood-brain barrier, for example, increasing bioavailability at diseased sites $[18,20,22]$.

Some studies demonstrated curcumin nanoformulations in the treatment of CNS diseases [23, 24]. In a study comparing free curcumin and its nanostructured form to reverse hippocampal damage in rats, a curcumin nanocomposite was superior to curcumin alone [25].

Curcumin and its nanoformulations possess several positive biological activities; however, few studies reported its safe concentrations in normal CNS cells. Such an evaluation is essential to determine safe concentrations of these agents that would permit further study [26-28].

Therefore, the objective of the present study was to determine non-toxic concentrations of free curcumin and two types of nanoformulations containing curcumin using cell lines derived from the CNS.

\section{Materials And Methods}

\section{Nanocapsules preparation}

Nanocapsules were developed using interfacial deposition of the preformed polymer, following the descriptions described by Jaguezeski et al. [29], with two polymers, poly- $\varepsilon$-caprolactone (PCL) (SigmaAldrich) or Eudragit L-100 (EDG) (Evonik).

In both formulations, the oil phase was poured into the aqueous phase and stirred for 15 minutes. The organic solvent was evaporated using a rotary evaporator. The PCL nanocapsule (NC-PCL) was developed containing $2 \mathrm{mg} / \mathrm{mL}$ of curcumin (Sigma-Aldrich), and the EDG nanocapsule (NC-EDG) was developed containing $0.25 \mathrm{mg} / \mathrm{mL}$. Nanocapsules without curcumin were also prepared (NB-PCL and NBEDG, respectively) [29].

\section{Nanocapsules characterization}

We used the dynamic light scattering technique to determine the mean particle size and polydispersity index (Zetasizer ${ }^{\circledR}$ nano-ZS model ZEN 3600, Malvern). The zeta potential (ZP) was determined using the electrophoretic mobility technique (Zetasizer ${ }^{\circledR}$ nano - ZS model ZEN 3600, Malvern) and pH was determined directly using a potentiometer (DM-22, Digimed®) [30].

The curcumin content in the nanocapsules was determined using high-performance liquid chromatography (HPLC). The encapsulation efficiency was determined using ultrafiltration-centrifugation with subsequent HPLC analysis according to the methodology described by Jaguezeski et al. [29].

\section{Cell culture}

Microglia cells (cell line BV-2) and neuron-like cells (cell line SH-SY5Y) were obtained from the Rio de Janeiro Cell Bank (ATCC® 0356, RJ, Brazil; ATCC® 0223, RJ, Brazil, respectively). BV-2 were cultured in RPMI-1640 medium (Sigma-Aldrich) containing 10 mM HEPES (Sigma-Aldrich), 10\% of fetal bovine 
serum (FBS) (Gibco® Thermo Fisher) and supplemented with $1 \%$ of antibiotic (100U/mL penicillin; $100 \mathrm{mg} / \mathrm{mL}$ streptomycin) (Gibco® Thermo Fisher). SH-SY5Y cells were cultured in Dulbecco's Modified Eagle Medium containing F12 supplement (Gibco ${ }^{\circledR}$ Thermo Fisher) with $10 \%$ FBS and $1 \%$ antibiotic. Cells were cultured at $37^{\circ} \mathrm{C}$ with $95 \%$ oxygen and $5 \% \mathrm{CO}_{2}$ until the numbers of cells were sufficient to perform the experimental treatments and analyses.

\section{Treatments}

BV-2 and SH-SY5Y cells were seeded in 96-well plates at $2.5 \times 10^{5}$ cells $/ \mathrm{mL}$. The neurotoxicities of free curcumin, NC-EDG, and NC-PCL were tested using a concentration-response curve (0.01-20 $\mu \mathrm{M})$ applied to both line cells at $24,48,72 \mathrm{~h}$ of exposure. For positive control, we used $25 \mu \mathrm{M}$ hydrogen peroxide $\left(\mathrm{H}_{2} \mathrm{O}_{2}\right)$ and negative control (CTL) only cells. We also used $1 \%$ ethanol as a control because curcumin was first diluted in this solvent. After the periods of incubation, cells were subjected to colorimetric and fluorometric assays.

\section{Mitochondrial viability}

Mitochondrial viability was measured using the MTT assay to measure cell viability or proliferative status. Cells were incubated with MTT reagent (3-(4,5-dimethyl-2-thiazolyl)-2,5-diphenyl-2H-tetrazolium bromide) (Sigma-Aldrich) at $5 \mathrm{mg} / \mathrm{mL}$ for up to $2 \mathrm{~h}$. Then, dimethylsulphoxide (Sigma-Aldrich) was added, and the absorbance was determined at $560 \mathrm{~nm}$ [31].

\section{Extracellular double-strand DNA quantification}

Quantification of extracellular-double-stand DNA (dsDNA) was performed in the cellular supernatants using the Quant-IT PicoGreen ${ }^{\circledR}$ dsDNA kit (Thermo Fischer). The reagent was added to each sample for 5 minutes at room temperature, avoiding light exposure. Emitted fluorescence was measured at $480 \mathrm{~nm}$ of excitation and $520 \mathrm{~nm}$ of emission [32].

\section{Reactive oxygen species levels}

The quantification of ROS production was conducted in supernatants using 2,7 dichlorodihydrofluorescein diacetate (DCFH-DA) reagent (Sigma-Aldrich). Fluorescence reading was performed at excitation of $485 \mathrm{~nm}$ and emission $520 \mathrm{~nm}$ after 1-hour incubation with the reagent at room temperature and under light protection [33].

\section{Nitric oxide levels}

The determination of NO present in the culture supernatant was based on an indirect measurement protocol published by Choi et al., which uses Griess reagent to detect organic nitrite. The absorbance was determined at $560 \mathrm{~nm}$ [34].

\section{Statistical analysis}

The results were transformed to percentages for the negative control group. Statistical differences between groups were analyzed using one-way ANOVA, followed by the Tukey test, using GraphPad Prism 
8 software. The data were presented as mean \pm SEM. Values were considered statistically significant when $P<0.05$.

\section{Results}

\section{Nanocapsules characterization}

The NC-PCL and NB-PCL formulations showed particle sizes of $194 \pm 0.31 \mathrm{~nm}$ and $188 \pm 1.10 \mathrm{~nm}$, respectively. NC-EDG measured $168 \pm 1.96 \mathrm{~nm}$, and NB-EDG were $169 \pm 1.08 \mathrm{~nm}$ in size. All formulations showed a polydispersion index of 0.1 , indicating size uniformity. The nanocapsules gave negative ZP and acidic $\mathrm{pH}$, characteristics of their constituents (NC-PCL: $-8.16 \pm 0.53 \mathrm{mV} ; 6.23 \pm 0.02$, NB-PCL: $-7.25 \pm$ $0.67 \mathrm{mV} ; 6.35 \pm 0.03$, NC-EDG: $-17.00 \pm 1.04 \mathrm{mV} ; 4.35 \pm 0.02$, NB-EDG: $-17.53 \pm 1.30 \mathrm{mV} ; 4.33 \pm 0.02$, respectively). The encapsulation efficiency of the nanoformulations was $100 \%$ in all cases, with curcumin concentrations of $0.25 \mathrm{mg} / \mathrm{ml}$ for NC-EDG and $2 \mathrm{mg} / \mathrm{ml}$ for NC-PCL (Supplemental Table 1).

\section{Curcumin treatments decrease or increase viability depending on the exposure time}

To determine the viability of BV-2 cells against exposure of treatments with free and nanoencapsulated curcumin, the MTT assay demonstrated, that $20 \mu \mathrm{M}$ of NB-EDG decreased microglial viability at $24 \mathrm{~h}$, as did 0.01 and $20 \mu \mathrm{M}$ NC-EDG. Treatment with NB-PCL showed no statistically significant difference; however, but $0.05,0.5$, and $1.0 \mu \mathrm{M}$ of NC-PCL stimulated proliferation (Fig. 1a).

After $48 \mathrm{~h}$ of exposure to treatments, only $20 \mu \mathrm{M}$ of NB-EDG increased cell viability (Fig. 1b). At $72 \mathrm{~h}$, the three lowest concentrations of NB-EDG and NC-EDG $(0.01,0.05$, and $0.1 \mu \mathrm{M})$ decreased cell viability in BV2 cells (Fig. 1C). By contrast, from $2.5 \mu \mathrm{M}$ to $20 \mu \mathrm{M}$, NC-EDG increased cell viability (Fig. 1c). Free curcumin showed no differences with the control group (Fig. 1a, 1b, and 1c).

SH-SY5Y cells are a subclone of neurons originating from human neuroblastoma. This cellular line is widely used for in vitro models of neural injuries, verifying the neurotoxicity of compounds and neuroprotection $[11,15,23]$.

The analysis of neuronal viability, over $24 \mathrm{~h}$ of exposure showed that $0.5,1.0,2.5$, and $5 \mu \mathrm{M}$, as well as 2.5 and $5.0 \mu \mathrm{M}$ of NB-EDG and NC-EDG, respectively, induced neuronal cell proliferation. On the contrary, was found in $0.01 \mu \mathrm{M}$ of NB-PCL (Fig. 1d).

At $48 \mathrm{~h}$, only $20 \mu \mathrm{M}$ of free curcumin reduced cell viability (Fig. 1e). When neuronal-like cells were incubated for $72 \mathrm{~h}, 0.5$ and $1.0 \mu \mathrm{M}$ NC-EDG increased cell viability (Fig. 1f).

\section{Curcumin nanocapsules induce membrane damage and DNA exposure}


Impacts of curcumin on BV-2 and SH-SY5Y cells were determined at 24, 48 and, $72 \mathrm{~h}$. Measurements of free dsDNA in the supernatants of BV-2 and SH-SY5Y cells are presented in Fig. 2. In BV-2 cells, 0.01, 0.05 , and $0.1 \mu \mathrm{M}$ of NB-EDG and NC-EDG were associated with less dsDNA at $24 \mathrm{~h}$, whereas the opposite occurred at the two highest concentrations (10 and $20 \mu \mathrm{M})$. At 0.05, 0.1, 0.5, and 1.0 $\mu \mathrm{M}, \mathrm{NC}-\mathrm{PCL}$ caused membrane damage, exposing the DNA in the supernatants (Fig. 2a).

At $48 \mathrm{~h}$, dsDNA content was lower than CTL, when $0.01,0.05$, and $0.1 \mu \mathrm{M}$ of NB-EDG and NC-EDG were used in BV-2 cells. A considerable increase of free dsDNA in supernatants was observed when 2.5 until 20 $\mu \mathrm{M}$ of NB-EDG and NC-EDG were added into the cell medium. The same occurred with $0.01,0.05,0.1$ and $1.0 \mu \mathrm{M}$ of NC-PCL. The free curcumin treatment was associated with a slight increase in free dsDNA at 1.0 and $2.5 \mu \mathrm{M}$ after exposure to BV-2 cells (Fig. $2 \mathrm{~b}$ ).

At $72 \mathrm{~h}$ after free curcumin or nanocapsules treatment of BV-2 cells, the dsDNA content in the supernatant showed increases for all nanoformulations (Fig. 2C). No significant results of free curcumin were observed in BV-2 cells (Fig. 2c).

The amount of free dsDNA in the supernatants of neuronal-like cells increased in a concentrationdependent manner for EDG nanoformulations. Concentrations of $0.1,0.5,10$, and $20 \mu \mathrm{M}$ of NC-PCL also increased levels of dsDNA at $24 \mathrm{~h}$ (Fig. 2d). At $48 \mathrm{~h}$ after exposure, the same occurred for nanoformulations with EDG. Nanocapsules with PCL also increased dsDNA content for all concentrations (Fig. 2e). At longer exposure times, dsDNA levels supernatants significantly increased with treatment of $20 \mu \mathrm{M}$ free curcumin, 1.0 to $20 \mu \mathrm{M}$ of NB-EDG, $0.5 \mu \mathrm{M}$ of NC-EDG and all concentrations of PCL nanocapsules (Fig. 2f).

\section{Curcumin nanocapsules modulated NO release in BV-2 and SH-SY5Y cells}

The BV-2 cell line originates from the microglia of C57BL/6 mouse brain tissue. We were used these cells because of their phagocytosis activity and involvement in neuroinflammation in brain [28]. To measure the effects of free curcumin and nanocapsules as a NO modulator, nitrite/nitrate levels were measured (Fig. 3).

The highest concentration of both curcumin nanocapsules $(20 \mu \mathrm{M})$ increased levels of NO in BV-2 cells at $24 \mathrm{~h}$ (Fig. 3a). After 48 and 72 h, only nanocapsules with EDG maintained the increase (Fig. 3b and 3c). In neuronal-like cells, NO levels were significantly increased in the $20 \mu \mathrm{M}$ treatments of NB-EDG and NC-EDG at all exposure times (Fig. 3d, 3e, and 3f).

\section{Modulatory effects of curcumin nanocapsules on ROS levels}

Several studies reported anti-oxidant effects of curcumin. Here, we sought to determine the optimal concentration to avoid ROS generation in BV2 and SH-SY5Y cells. We found lower ROS levels $24 \mathrm{~h}$ after application of free curcumin (10 and $20 \mu \mathrm{M})$, NB-EDG (0.01 up to $5.0 \mu \mathrm{M})$, NC-EDG $(0.01$ up to $20 \mu \mathrm{M})$, 
NB-PCL $(0.01,0.05,0.5,1.0$ and $5.0 \mu \mathrm{M})$, and NC-PCL $(0.01 \mu \mathrm{M}$ and 0.5 up to $20 \mu \mathrm{M})$ in BV-2 cells than in CTL (Fig. 4a).

At $48 \mathrm{~h}$ after nanocapsules treatments, ROS levels increased when NB-EDG (10 and $20 \mu \mathrm{M})$, NB-PLC (1.0, 2.5, and $20 \mu \mathrm{M})$, or NC-PCL (0.05 and $0.1 \mu \mathrm{M})$ were used when compared to CTL (Fig. 4b). In contrast, high-concentration free curcumin $(20 \mu \mathrm{M})$ gave lower ROS levels than CTL in BV-2 cells (Fig. 4b).

At the end of the experiment, the addition of free curcumin $(0.05 \mu \mathrm{M})$, NB-EDG $(0.1,0.5,2.5$, and $10 \mu \mathrm{M})$ gave higher ROS levels than CTL in BV-2 cells (Fig. 4c). By contrast, free curcumin (20 $\mu \mathrm{M}), \mathrm{NB}-\mathrm{PCL}(0.01$ up to $10 \mu \mathrm{M})$, and NC-PCL (0.01 up to $20 \mu \mathrm{M})$ significantly diminished ROS levels in BV-2 cell compared to the CTL (Fig. 4c).

In SH-SY5Y cell, ROS production also increased for all nanocapsule preparations; curcumin groups showed no significant changes after $24 \mathrm{~h}$ (Fig. 4d). Our results demonstrate decreased ROS levels according to the concentration of NC-EDG (from $1.0 \mu \mathrm{M}$. The same happened when the cells were exposed to NC-PCL for $48 \mathrm{~h}$. From $5 \mu \mathrm{M}$ of curcumin, ROS levels also decreased (Fig. 4e). The two curcumin nanoformulations decreased ROS production from the $2.5 \mu \mathrm{M}$ concentration and 10 and $20 \mu \mathrm{M}$ of free curcumin; however, only $0.01 \mu \mathrm{M}$ of free curcumin was associated with increased ROS production (Fig. 4f).

\section{Discussion}

Screening of natural compounds is critically important, because they are increasingly used to prevent morbidities without proper monitoring [35]. In particular, curcumin has many beneficial effects; however, its low bioavailability and rapid metabolism suggest the need for nanoformulations $[21,36]$.

In the present study, two curcumin nanoformulations were prepared, NC-EDG and NC-PCL. We also prepared two nanoformulations without curcumin to serve as controls. The physio-chemical characteristics of both curcumin nanocapsules showed an efficiency of encapsulation and uniformity of nanometric size; these results were satisfactory according to the production protocol established by our research group $[29,30]$.

Curcumin has been considered a promising approach to the treatment of several brain disorders. We determined cytotoxicity parameters of free curcumin and curcumin-loaded nanocapsules measured as cell death, proliferation and oxidative profile. In vitro experimental models are useful tools because they provide preliminary profiles of cellular responses and possible damages that could occur, guiding subsequent studies [37, 38].

A review by Soleimani, Sahebkar, and Hosseinzadeh discussed the safety and toxicity of curcumin in in vitro and in vivo models, both in animal and human trials [26]. According to the authors, curcumin was non-toxic up to specific concentrations, depending on the model studied. Nevertheless, the use of curcumin nanoformulations needs to be explored in more depth. The authors indicated that curcumin is 
non-mutagenic and safe for pregnant animals; however, this assertion should be tested carefully [26]. In agreements, some authors defended the notion that nanoencapsulated medications should be tested for their safety. We evaluated NC-PCL and NC-EDG and free curcumin in microglial and neuronal-like cell lines at different incubation periods.

In BV-2 cells, at $24 \mathrm{~h}$ after exposure, we found that free curcumin at the two highest concentrations decreased ROS production and $0.5-2.5 \mu \mathrm{M}$ of NC-EDG and 2.5 and $5 \mu \mathrm{M}$ for NC-PCL were safe to use in vitro, in that they did not compromise cell homeostasis. However, at $48 \mathrm{~h}$ of exposure, specific concentrations of the nanoformulations unbalanced the oxidative profile. The amount of free DNA increased, suggesting that the non-toxic concentrations were $0.5-1.0 \mu \mathrm{M}$ for NC-EDG and 2.5 $\mu \mathrm{M}$ for NC$\mathrm{PCL}$, in this situation. With longer exposure times, the amount of free dsDNA was highly significant for all nanoformulations, suggesting possible membrane damage; this finding can be explained by the interaction of the polymers that make up the nanocapsule with the cell membrane, increasing permeability $[36,39]$. By contrast, curcumin alone did not cause membrane damage at $72 \mathrm{~h}$.

Exposure of these agents to neuronal-like cells showed that curcumin nanocapsules were associated with increased ROS levels, suggesting oxidative stress. NC-EDG was associated with high dsDNA levels at all concentrations, suggesting membrane damage, possibly due to EDG interacting with the cell membrane. At $48 \mathrm{~h}$, the amount of free dsDNA also increased. By contrast, from $1.0 \mu \mathrm{M}$ of nanoformulations, ROS production decreased, suggesting that perhaps the nanocapsules positively modulated oxidative mechanism. Curcumin was safe up to $10 \mu \mathrm{M}$; however, it was associated with ROS levels from $2.5 \mu \mathrm{M}$. At $72 \mathrm{~h}$, the changes were more significant, suggesting compromised cellular homeostasis.

The antioxidant properties of curcumin are among the essential features that raise its therapeutic value. Severe oxidative stress is a cause of neural loss in the context of brain disorders [5]. The production of ROS and NO, under conditions of homeostasis, occurs as part of cellular physiological metabolism and is essential for the organism to identify and eliminate stressors agent. Decreased ROS levels can be harmful under normal conditions but not during diseases treatment. The mechanisms by which curcumin decrease ROS levels, unbalancing the compromising antioxidant profile, involve its antioxidant activity, which neutralizes ROS formed by cells $[1,2,5,6,40]$. Studies showed that cancer cells are more susceptible to curcumin than normal cells; curcumin's mechanism of action involves the regulation of ROS production, depending on cell type and experimental conditions [40-43].

Here, we demonstrated that 10 and $20 \mu \mathrm{M}$ of curcumin, depending on the exposure time, were harmful to cells, causing lower cell viability. In contrast, intermediate curcumin concentrations showed less neurotoxicity compared to the same concentrations of nanoformulations, as these obtained more significant statistical results when compared with negative control. This can be explained by the fact that nanoformulations have components that generate cytotoxicity, including the surfactant polysorbate 80 . This fact also explains decreased or increased cell viability, membrane damage, and imbalance in levels of ROS and NO in nanoformulations that did not contain curcumin, used here as controls [39]. 
Comparing the two curcumin nanoformulations, NC-PCL showed better results than NC-EDG, indicated by the lower significance levels when compared to negative control; however, the optimal choice for use in subsequent experiments will depend on the investigation experimental design because NC-PCL is more suitable for parenteral administration and NC-EDG is better for the oral route; this is because the constituent polymers differ for each nanocapsule. It is also important to highlight that in vitro screening tests are very important; however, results obtained in vivo may present different results, due to the consideration of an organism and its metabolism as a whole $[20,36]$.

It is important to note that cellular behavior, oxidative status depended on the exposure time. Damage increased over time primarily due to the high levels of free DNA in the supernatants in BV-2 cells and high levels of NO for $20 \mu \mathrm{M}$ of NC-EDG. These characteristics must be considered when formulating the experimental design of a study.

No studies focused on safe concentration-response curves of curcumin in healthy cells originating from the CNS,; few studies are the same in healthy cells from tissue sources [28, 44-47]. However, in animals, the ethanolic extract of the rhizomes of $C$. longa, when administered chronically, changed the weight of the heart and lung [27]. Corroborating this, Balaji and Chempakam demonstrated the toxicity of several components of $C$. longa, among them curcumin, with dose-dependent hepatotoxicity [46].

Cancer cell lines have been used to determinate the ideal concentration of curcumin treatment and neural lines for brain injuries in vitro models.

In the PC12 cancer cells, curcumin decreased cell viability in a concentration dependent manner [48]. Using microglial BV-2 cells, Zhang et al. found that curcumin inhibited lipopolysaccharide-induced neuroinflammation at $1,5,10,20$, and $40 \mu \mathrm{M}$ [49]. Curcumin also inhibited oxidative stress by decreasing ROS in a model of neurodegenerative disease with SH-SY5Y cells at 1, 2.5, and $5 \mu \mathrm{M}$ [15]. Mursaleen et al. used curcumin nanoformulation 5 and $10 \mu \mathrm{M}$ to protect the cells against neurotoxicity induced by rotenone in SH-SY5Y cells [23].

These studies demonstrate that our results for safe concentrations of curcumin are in line with those used to treat diseases that affect the CNS. Therefore, concentrations between 1.0 to $5 \mu \mathrm{M}$ are not harmful to healthy cells. Nevertheless, because of the disadvantages of the substance in free form, nanoformulations at the same concentrations or even lower than those mentioned may deliver more satisfactory results by controlling the release of curcumin and increasing its bioavailability, in addition to crossing the blood-brain barrier and reaching the sites of brain injuries $[18,21,22]$.

According to our introductory innovative study, that determined the non-neurotoxic concentrations of curcumin nanoformulations and their free form, researchers can use our findings as a basis for choosing the optimal concentrations for their experimental models. It is essential to use safe concentrations to analyze the pharmacological potential of natural products. Because the present study was a proof of concept study, more specific investigations and in vivo experimental models must be carried out to test our findings. 


\section{Conclusion}

Curcumin nanoformulations using PCL and EDG in BV-2 and SH-SY5Y cells were more toxic than free curcumin. We suggest that 1.0-5 $\mu \mathrm{M}$ of free curcumin and curcumin nanocapsules may be useful for the treating or preventing diseases that affect the CNS, as they do not cause collateral damage to healthy cells.

\section{Declarations}

\section{Funding}

BFB and PMC are grateful to Coordenação de Aperfeiçoamento de Pessoal de Nível Superior CAPES/PROEX process $n^{\circ} 88887.372278 / 2019-00$ and 88887.372294/2019-00.

\section{Conflicts of interest}

The authors declare no conflicts of interest.

\section{Availability of data and material}

The raw data generated during the study are available from the corresponding author on reasonable request. All results generated and analysed during this study are included in this published article and its supplementary material.

\section{Code availability}

Not applicable.

\section{Author contributions}

BFB and PMC equally performed the experiments, data analysis, and manuscript draft. SSG and AFS produced and characterized the nanocapsules. AKM, MRS, VMM, NBB, and ASS revised the manuscript and funding reagents. All authors read and approved the publication of this manuscript.

\section{Research involving human participants and/or animals}

Not applicable

\section{Ethics approval}

Not applicable

\section{Consent to participate}

Not applicable 


\section{Consent for publication}

Not applicable

\section{References}

1. Ayati Z, Ramezani M, Amiri MS, et al (2019) Ethnobotany, Phytochemistry and Traditional Uses of Curcuma spp. and Pharmacological Profile of Two Important Species (C. longa and C. zedoaria): A Review. Curr Pharm Des 25:871-935. https://doi.org/10.2174/1381612825666190402163940

2. Tomeh MA, Hadianamrei R, Zhao X (2019) A review of curcumin and its derivatives as anticancer agents. Int J Mol Sci 20:1033. https://doi.org/10.3390/ijms20051033

3. Khazdair MR, Anaeigoudari A, Hashemzehi M, Mohebbati R (2019) Neuroprotective potency of some spice herbs, a literature review. J Tradit Complement Med 9:98-105. https://doi.org/10.1016/j.jtcme.2018.01.002

4. Willenbacher E, Khan SZ, Mujica SCA, et al (2019) Curcumin: New insights into an ancient ingredient against cancer. Int J Mol Sci 20:1-13. https://doi.org/10.3390/ijms20081808

5. Hewlings S, Kalman D (2017) Curcumin: A Review of Its Effects on Human Health. Foods 6:92. https://doi.org/10.3390/foods6100092

6. Camacho-Barquero L, Villegas I, Sánchez-Calvo JM, et al (2007) Curcumin, a Curcuma longa constituent, acts on MAPK p38 pathway modulating COX-2 and iNOS expression in chronic experimental colitis. Int Immunopharmacol 7:333-342.

https://doi.org/10.1016/j.intimp.2006.11.006

7. Maiti P, Dunbar G (2018) Use of Curcumin, a Natural Polyphenol for Targeting Molecular Pathways in Treating Age-Related Neurodegenerative Diseases. Int J Mol Sci 19:1637. https://doi.org/10.3390/ijms19061637

8. Bagheri $\mathrm{H}$, Ghasemi F, Barreto $\mathrm{GE}$, et al (2020) Effects of curcumin on mitochondria in neurodegenerative diseases. BioFactors 46:5-20. https://doi.org/c

9. Bhat A, Mahalakshmi AM, Ray B, et al (2019) Benefits of curcumin in brain disorders. BioFactors 45:666-689. https://doi.org/10.1002/biof.1533

10. da Costa IM, de Moura Freire MA, de Paiva Cavalcanti JRL, et al (2018) Supplementation with Curcuma longa Reverses Neurotoxic and Behavioral Damage in Models of Alzheimer's Disease: A Systematic Review. Curr Neuropharmacol 17:406-421. https://doi.org/10.2174/0929867325666180117112610

11. Armağan HH, Nazıroğlu M (2020) Curcumin Attenuates Hypoxia-Induced Oxidative Neurotoxicity, Apoptosis, Calcium, and Zinc lon Influxes in a Neuronal Cell Line: Involvement of TRPM2 Channel. Neurotox Res. https://doi.org/10.1007/s12640-020-00314-w

12. Fan C, Song Q, Wang P, et al (2019) Neuroprotective effects of curcumin on IL-1ß-induced neuronal apoptosis and depression-like behaviors caused by chronic stress in rats. Front Cell Neurosci 12:117. https://doi.org/10.3389/fncel.2018.00516 
13. Wang Z, Yang C, Liu J, et al (2020) A curcumin derivative activates TFEB and protects against parkinsonian neurotoxicity in vitro. Int J Mol Sci 21:1515. https://doi.org/10.3390/ijms21041515

14. Wei W, Dong Q, Jiang W, et al (2021) Dichloroacetic acid-induced dysfunction in rat hippocampus and the protective effect of curcumin. Metab Brain Dis 36:545-556. https://doi.org/10.1007/s11011020-00657-5

15. Xiang B, Li D, Chen Y, et al (2020) Curcumin Ameliorates Copper-Induced Neurotoxicity Through Inhibiting Oxidative Stress and Mitochondrial Apoptosis in SH-SY5Y Cells. Neurochem Res 46:367378. https://doi.org/10.1007/s11064-020-03173-1

16. Khan MS, Muhammad T, Ikram M, Kim MO (2019) Dietary Supplementation of the Antioxidant Curcumin Halts Systemic LPS-Induced Neuroinflammation-Associated Neurodegeneration and Memory/Synaptic Impairment via the JNK/NF- K B/Akt Signaling Pathway in Adult Rats. Oxid Med Cell Longev 2019:1-23. https://doi.org/10.1155/2019/7860650

17. Namgyal D, Ali S, Mehta R, Sarwat M (2020) The neuroprotective effect of curcumin against Cdinduced neurotoxicity and hippocampal neurogenesis promotion through CREB-BDNF signaling pathway. Toxicology 442:152542. https://doi.org/10.1016/j.tox.2020.152542

18. Rakotoarisoa M, Angelova A (2018) Amphiphilic Nanocarrier Systems for Curcumin Delivery in Neurodegenerative Disorders. Medicines 5:126. https://doi.org/10.3390/medicines5040126

19. Vaiserman A, Koliada A, Lushchak O (2020) Neuroinflammation in pathogenesis of Alzheimer's disease: Phytochemicals as potential therapeutics. Mech Ageing Dev 189:111259. https://doi.org/10.1016/j.mad.2020.111259

20. Ahmed K, Li Y, McClements DJ, Xiao H (2012) Nanoemulsion- and emulsion-based delivery systems for curcumin: Encapsulation and release properties. Food Chem 132:799-807. https://doi.org/10.1016/j.foodchem.2011.11.039

21. Del Prado-Audelo ML, Caballero-Florán IH, Meza-Toledo JA, et al (2019) Formulations of curcumin nanoparticles for brain diseases. Biomolecules 9:1-28. https://doi.org/10.3390/biom9020056

22. Sadegh Malvajerd S, Azadi A, Izadi Z, et al (2019) Brain Delivery of Curcumin Using Solid Lipid Nanoparticles and Nanostructured Lipid Carriers: Preparation, Optimization, and Pharmacokinetic Evaluation. ACS Chem Neurosci 10:728-739. https://doi.org/10.1021/acschemneuro.8b00510

23. Mursaleen L, Somavarapu S, Zariwala MG (2020) Deferoxamine and Curcumin Loaded Nanocarriers Protect Against Rotenone-Induced Neurotoxicity. J Parkinsons Dis 10:99-111. https://doi.org/10.3233/JPD-191754

24. Azami SJ, Teimouri A, Keshavarz H, et al (2018) Curcumin nanoemulsion as a novel chemical for the treatment of acute and chronic toxoplasmosis in mice. Int J Nanomedicine 13:7363-7374. https://doi.org/10.2147/IJN.S181896

25. Zaki SM, Algaleel WAA, Imam RA, et al (2020) Nano-curcumin versus curcumin in amelioration of deltamethrin-induced hippocampal damage. Histochem Cell Biol 154:157-175. https://doi.org/10.1007/s00418-020-01871-z 
26. Soleimani V, Sahebkar A, Hosseinzadeh H (2018) Turmeric (Curcuma longa) and its major constituent (curcumin) as nontoxic and safe substances: Review. Phyther Res 32:985-995. https://doi.org/10.1002/ptr.6054

27. Qureshi S, Shah AH, Ageel AM (1992) Toxicity studies on Alpinia galanga and Curcuma longa. Planta Med 58:124-127. https://doi.org/10.1055/s-2006-961412

28. Ghasemi F, Bagheri H, Barreto GE, et al (2019) Effects of Curcumin on Microglial Cells. Neurotox Res 36:12-26. https://doi.org/10.1007/s12640-019-00030-0

29. Jaguezeski AM, Gündel SS, Favarin FR, et al (2019) Low-dose curcumin-loaded Eudragit L-100nanocapsules in the diet of dairy sheep increases antioxidant levels and reduces lipid peroxidation in milk. J Food Biochem 43:1-14. https://doi.org/10.1111/jfbc.12942

30. Gündel SS, Velho MC, Diefenthaler MK, et al (2018) Basil oil-nanoemulsions: Development, cytotoxicity and evaluation of antioxidant and antimicrobial potential. J Drug Deliv Sci Technol 46:378-383. https://doi.org/10.1016/j.jddst.2018.05.038

31. Fukui M, Choi HJ, Zhu BT (2010) Mechanism for the protective effect of resveratrol against oxidative stress-induced neuronal death. Free Radic Biol Med 49:800-813.

https://doi.org/10.1016/j.freeradbiomed.2010.06.002

32. Ahn S, Costa J, Emanuel J. (1996) PicoGreen quantitation of DNA: effective evaluation of samples pre- or post-PCR. Nucleic Acids Res 24:2623-2625. https://doi.org/10.1093/nar/24.13.2623

33. Costa F, Dornelles E, Mânica-Cattani MF, et al (2012) Influence of Val16Ala SOD2 polymorphism on the in-vitro effect of clomiphene citrate in oxidative metabolism. Reprod Biomed Online 24:474-481. https://doi.org/10.1016/j.rbmo.2012.01.009

34. Choi W, Shin P, Lee J, Kim G (2012) The regulatory effect of veratric acid on NO production in LPSstimulated. Cell Immunol 280:164-170. https://doi.org/10.1016/j.cellimm.2012.12.007

35. Parasuraman S (2011) Toxicological screening. J Pharmacol Pharmacother 2:74-79. https://doi.org/10.4103/0976-500X.81895

36. Umerska A, Gaucher C, Oyarzun-Ampuero F, et al (2018) Polymeric nanoparticles for increasing oral bioavailability of Curcumin. Antioxidants 7:46. https://doi.org/10.3390/antiox7040046

37. Eisenbrand G, Pool-Zobel B, Baker V, et al (2002) Methods of in vitro toxicology. Food Chem Toxicol 40:193-236. https://doi.org/10.1016/S0278-6915(01)00118-1

38. Gartlon J, Kinsner A, Bal-Price A, et al (2006) Evaluation of a proposed in vitro test strategy using neuronal and non-neuronal cell systems for detecting neurotoxicity. Toxicol Vitr 20:1569-1581. https://doi.org/10.1016/j.tiv.2006.07.009

39. Zielińska A, Carreiró F, Oliveira AM, et al (2020) Polymeric Nanoparticles: Production, Characterization, Toxicology and Ecotoxicology. Molecules 25:3731. https://doi.org/10.3390/molecules25163731

40. Liczbiński P, Michałowicz J, Bukowska B (2020) Molecular mechanism of curcumin action in signaling pathways: Review of the latest research. Phyther Res 34:1992-2005. https://doi.org/10.1002/ptr.6663 
41. Nakamae I, Morimoto T, Shima H, et al (2019) Curcumin derivatives verify the essentiality of ROS upregulation in tumor suppression. Molecules 24:1-25. https://doi.org/10.3390/molecules24224067

42. Barzegar A, Moosavi-Movahedi AA (2011) Intracellular ROS protection efficiency and free radicalscavenging activity of curcumin. PLoS One 6:1-7. https://doi.org/10.1371/journal.pone.0026012

43. Fujisawa S, Atsumi T, Ishihara M, Kadoma Y (2004) Cytotoxicity, ROS-generation Activity and Radical-scavenging Activity of Curcumin and Related Compounds. Anticancer Res 24:563-569

44. Syng-Ai C, Kumari AL, Khar A (2004) Effect of curcumin on normal and tumor cells: Role of glutathione and bcl-2. Mol Cancer Ther 3:1101-1108

45. Bala K, Tripathy BC, Sharma D (2006) Neuroprotective and anti-ageing effects of curcumin in aged rat brain regions. Biogerontology 7:81-89. https://doi.org/10.1007/s10522-006-6495-x

46. Balaji S, Chempakam B (2010) Toxicity prediction of compounds from turmeric (Curcuma longa $L$ ). Food Chem Toxicol 48:2951-2959. https://doi.org/10.1016/j.fct.2010.07.032

47. Kunwar A, Barik A, Mishra B, et al (2008) Quantitative cellular uptake, localization and cytotoxicity of curcumin in normal and tumor cells. Biochim Biophys Acta - Gen Subj 1780:673-679. https://doi.org/10.1016/j.bbagen.2007.11.016

48. Mendonça LM, dos Santos GC, Antonucci GA, et al (2009) Evaluation of the cytotoxicity and genotoxicity of curcumin in PC12 cells. Mutat Res - Genet Toxicol Environ Mutagen 675:29-34. https://doi.org/10.1016/j.mrgentox.2009.02.003

49. Zhang J, Zheng Y, Luo Y, et al (2019) Curcumin inhibits LPS-induced neuroinflammation by promoting microglial M2 polarization via TREM2/ TLR4/ NF-KB pathways in BV2 cells. Mol Immunol 116:29-37. https://doi.org/10.1016/j.molimm.2019.09.020

\section{Figures}




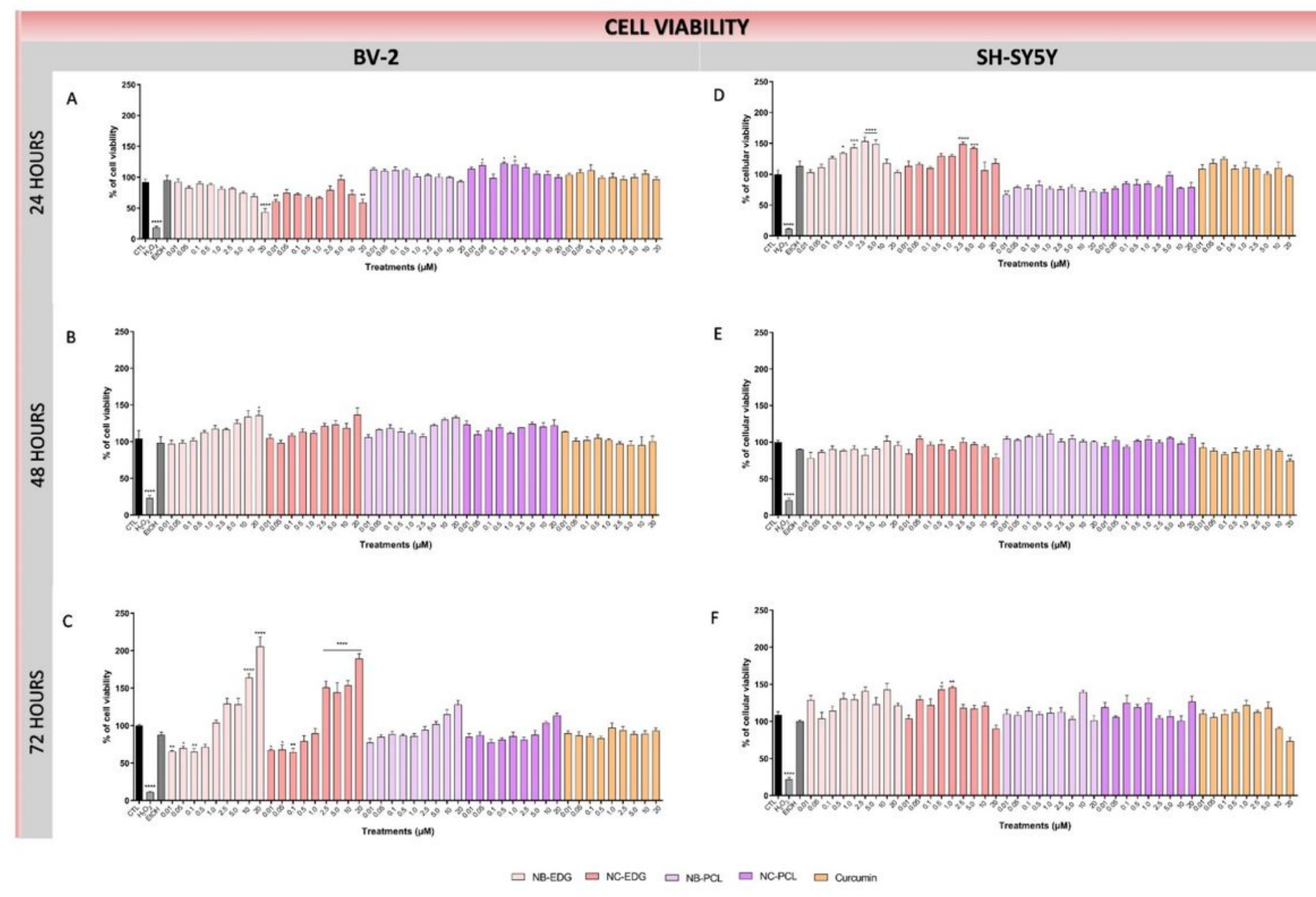

\section{Figure 1}

Cellular viability or proliferative status using MTT assay. a BV-2 cells after $24 \mathrm{~h}$ of exposure to curcumin treatments. b BV-2 cells after $48 \mathrm{~h}$ of exposure to curcumin treatments. c BV-2 cells after $72 \mathrm{~h}$ of exposure to curcumin treatments. $\mathrm{d}$ SH-SY $5 Y$ cells after $24 \mathrm{~h}$ of exposure to curcumin treatments. e SH-SY5Y cells after $48 \mathrm{~h}$ of exposure to curcumin treatments. $\mathrm{SH}-\mathrm{SY} 5 \mathrm{Y}$ cells after $72 \mathrm{~h}$ of exposure to curcumin treatments. NB-EDG: nanocapsule of EDG without curcumin; NC-EDG: nanocapsule of EDG with curcumin; NB-PCL: nanocapsule of PCL without curcumin; NC-PCL: nanocapsule of PCL with curcumin; Curcumin: free curcumin; CTL: negative control. Statistical analysis was performed comparing treatment groups with the negative control. ${ }^{*} \mathrm{P}<0.05,{ }^{\star *} \mathrm{P}<0.01$, ${ }^{\star \star \star} \mathrm{P}<0.001$, ${ }^{\star \star \star *} \mathrm{P}<0.0001$. 


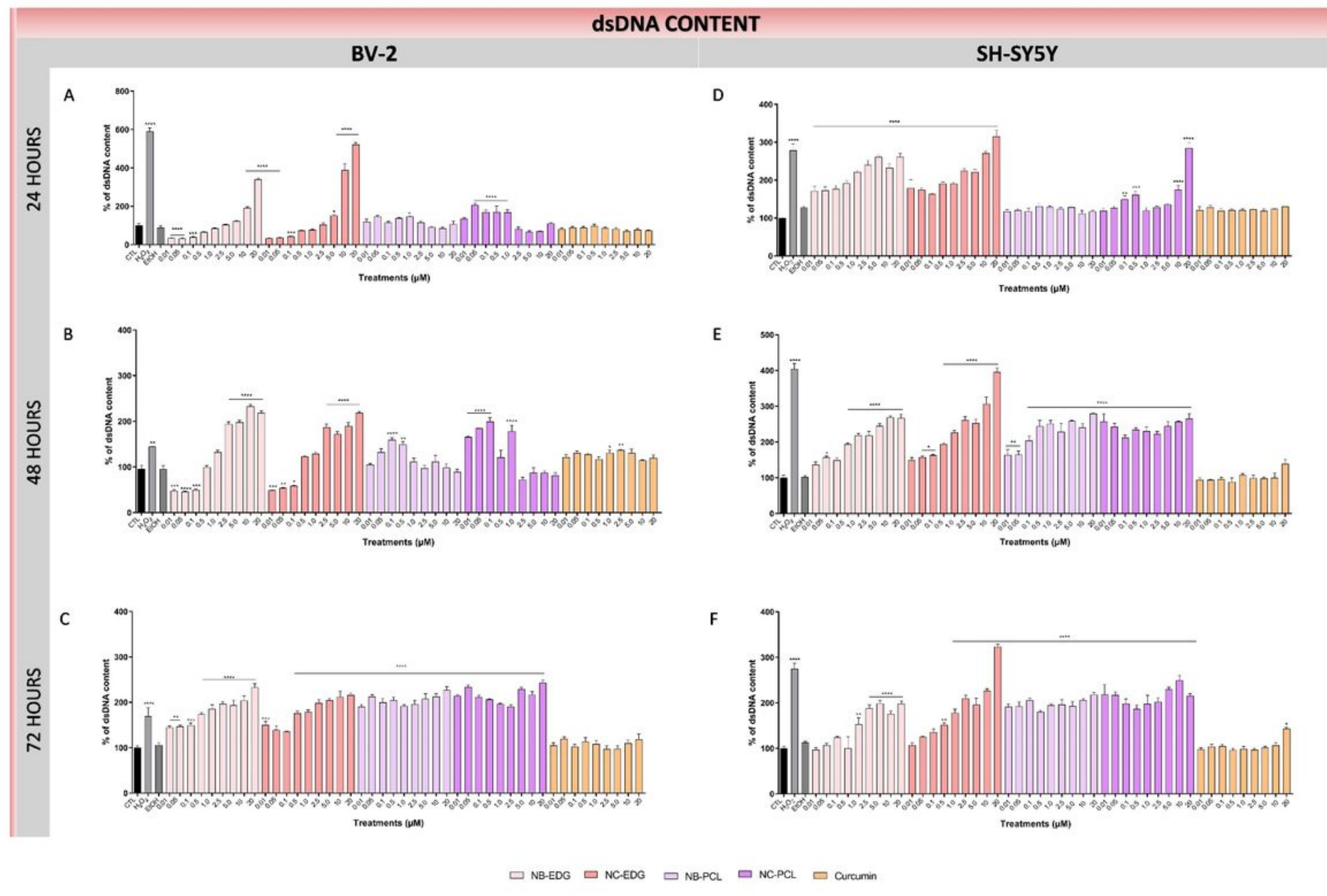

Figure 2

Membrane damage and DNA exposure using the PicoGreen assay. a BV-2 cells after $24 \mathrm{~h}$ of exposure to curcumin treatments. b BV-2 cells after $48 \mathrm{~h}$ of exposure to curcumin treatments. c BV-2 cells after $72 \mathrm{~h}$ of exposure to curcumin treatments. $\mathrm{d}$ SH-SY5Y cells after $24 \mathrm{~h}$ of exposure to curcumin treatments. e SH-SY5Y cells after $48 \mathrm{~h}$ of exposure to curcumin treatments. $\mathrm{f} \mathrm{SH-SY5Y}$ cells after $72 \mathrm{~h}$ of exposure to curcumin treatments. NB-EDG: nanocapsule of EDG without curcumin; NC-EDG: nanocapsule of EDG with curcumin; NB-PCL: nanocapsule of PCL without curcumin; NC-PCL: nanocapsule of PCL with curcumin; Curcumin: free curcumin; CTL: negative control. Statistical analysis was performed comparing treatment groups with the negative control. ${ }^{\star} P<0.05,{ }^{\star *} \mathrm{P}<0.01$, ${ }^{\star \star \star} \mathrm{P}<0.001,{ }^{\star \star \star \star} \mathrm{P}<0.0001$ 


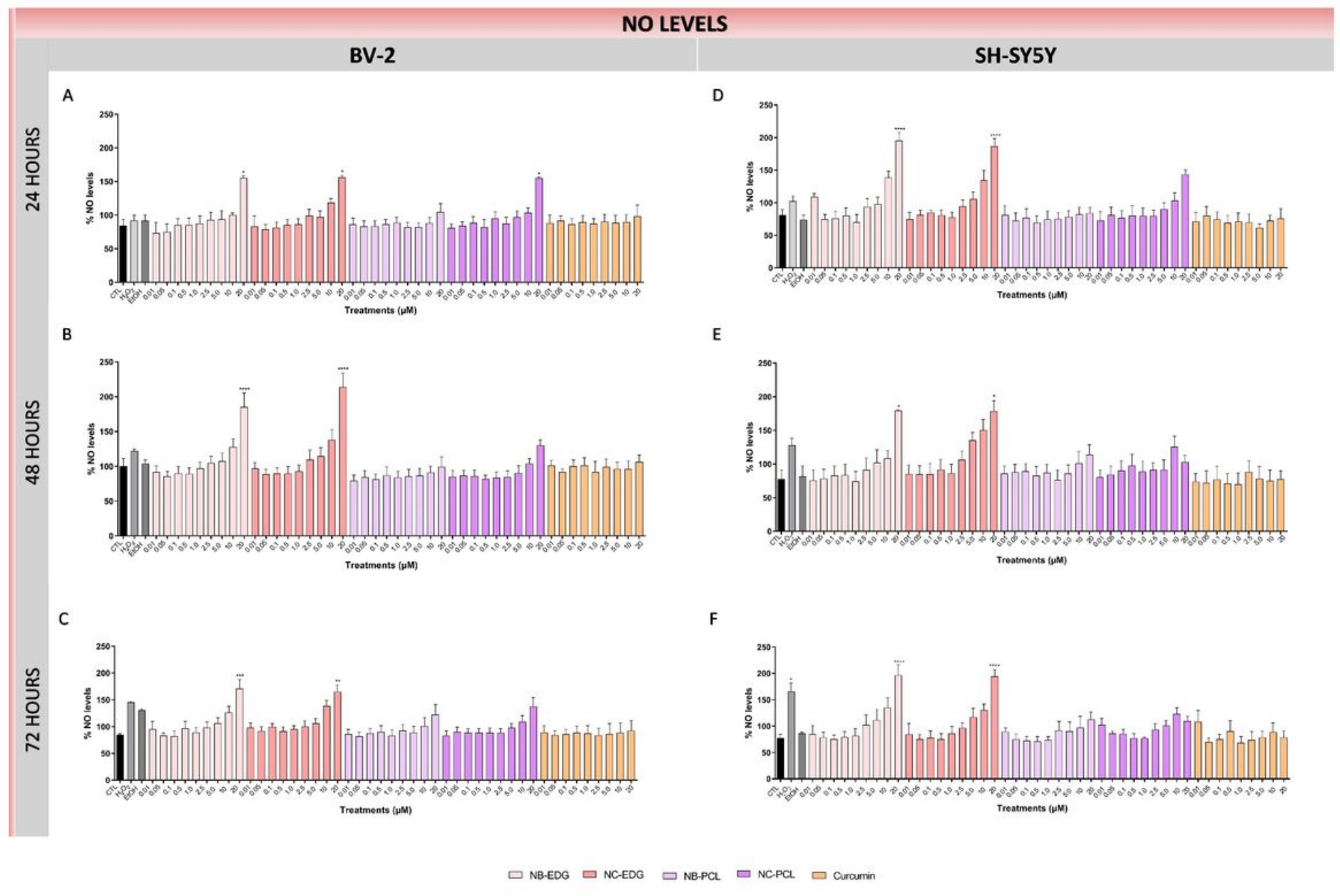

Figure 3

NO levels in supernatants using Griess reagent. a BV-2 cells after $24 \mathrm{~h}$ of exposure to curcumin treatments. b BV-2 cells after $48 \mathrm{~h}$ of exposure to curcumin treatments. c BV-2 cells after $72 \mathrm{~h}$ of exposure to curcumin treatments. $\mathrm{d}$ SH-SY $5 Y$ cells after $24 \mathrm{~h}$ of exposure to curcumin treatments. e SH-SY5Y cells after $48 \mathrm{~h}$ of exposure to curcumin treatments. $\mathrm{S} \mathrm{SH-SY5Y}$ cells after $72 \mathrm{~h}$ of exposure to curcumin treatments. NB-EDG: nanocapsule of EDG without curcumin; NC-EDG: nanocapsule of EDG with curcumin; NB-PCL: nanocapsule of PCL without curcumin; NC-PCL: nanocapsule of PCL with curcumin; Curcumin: free curcumin; CTL: negative control. Statistical analysis was performed comparing treatment groups with the negative control. ${ }^{*} P<0.05,{ }^{* * P}<0.01,{ }^{\star *} * \mathrm{P}<0.001$, ${ }^{\star \star \star *} \mathrm{P}<0.0001$. 


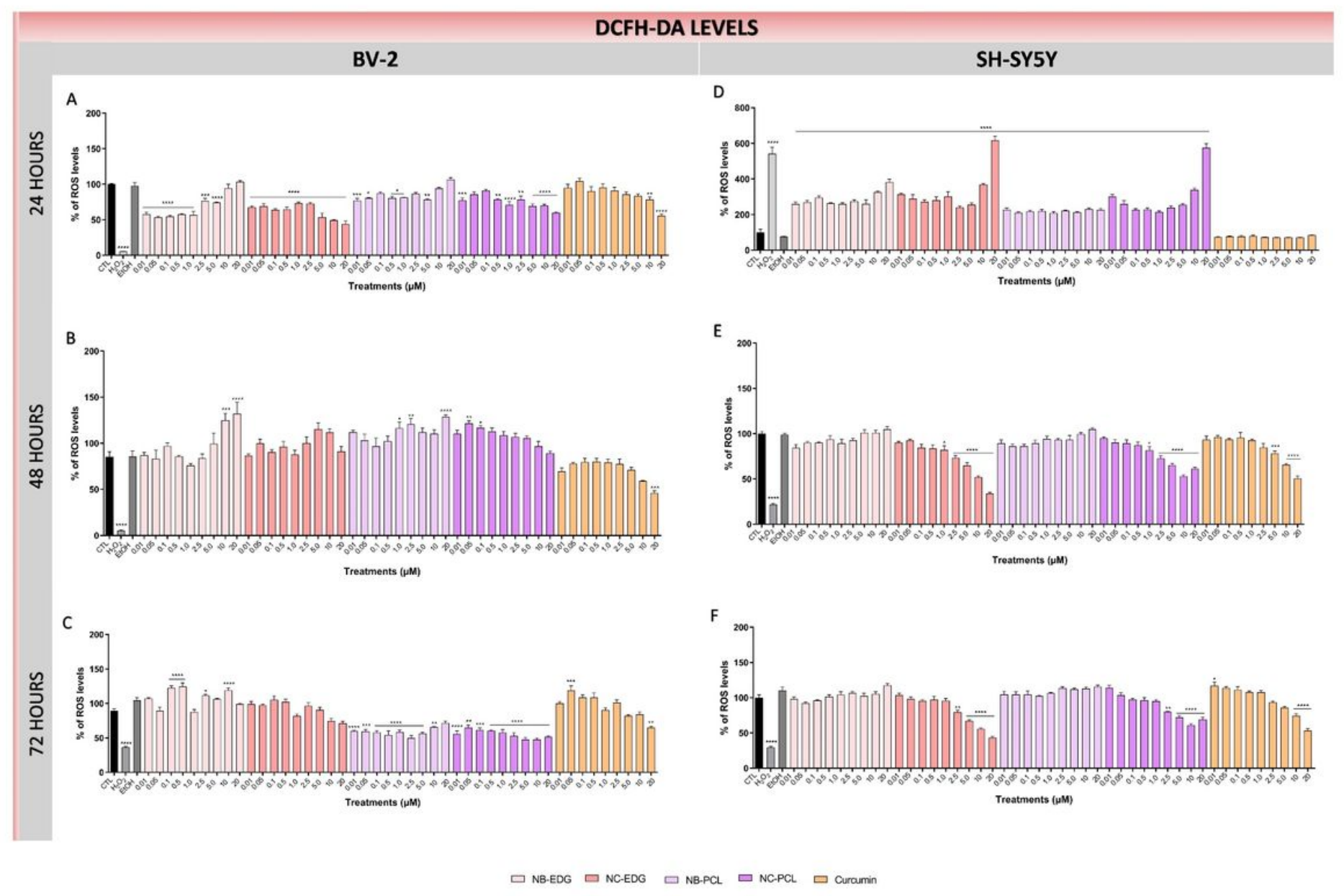

\section{Figure 4}

ROS levels in supernatants using DCFH-DA reagent. a BV-2 cells after 24 hours of exposure to curcumin treatments. b BV-2 cells after $48 \mathrm{~h}$ of exposure to curcumin treatments. c BV-2 cells after $72 \mathrm{~h}$ of exposure to curcumin treatments. $\mathrm{d} \mathrm{SH-SY} 5 Y$ cells after 24 hours of exposure to curcumin treatments. e SH-SY5Y cells after 48 hours of exposure to curcumin treatments. f SH-SY5Y cells after 72 hours of exposure to curcumin treatments. NB-EDG: nanocapsule of EDG without curcumin; NC-EDG: nanocapsule of EDG with curcumin; NB-PCL: nanocapsule of PCL without curcumin; NC-PCL: nanocapsule of PCL with curcumin; Curcumin: free curcumin; CTL: negative control. Statistical analysis was performed comparing treatment groups with the negative control. ${ }^{*} P<0.05,{ }^{\star} * \mathrm{P}<0.01$, ${ }^{\star \star *} \mathrm{P}<0.001$, $* \star \star \star P<0.0001$.

\section{Supplementary Files}

This is a list of supplementary files associated with this preprint. Click to download.

- SuplementarMaterial.docx 